\title{
SISTEM PRESENSI SISWA BERBASIS INTERNET OF THINGS MENGGUNAKAN SENSOR SIDIK JARI PADA SMK PERHOTELAN 45 MATARAM
}

\author{
(Student Attendance System Using Fingerprint Sensor on the SMK Perhotelan 45 \\ Mataram Based on Internet of Things)
}

\author{
Baiq Rizki Putri Utami", I Wayan Agus Arimbawa, Fitri Bimantoro \\ Dept Informatics Engineering, Mataram University \\ Jl. Majapahit 62, Mataram, Lombok NTB, INDONESIA
}

Email: utamikikiputri@gmail.com, arimbawa@unram.ac.id, bimo@unram.ac.id

\begin{abstract}
The utilizing of fingerprint biometric technology can be a solution that helps minimize errors or fraud such as manipulation or falsification in the process of recording student attendance. SMK Perhotelan 45 Mataram is a Vocational High School which still applies conventional attendance records by recording student attendance in monthly attendance books, so it is necessary to apply computerized attendance records by utilizing the concept of the Internet of Things (IOT) which assumes that electronic devices can connect with each other to communicate and exchange data independently through the internet using protocols. MQTT (Message Queue Telemetry Transport) is a lightweight message protocol and is designed for loT devices with limited resources. In this study, a presence system was created for students of SMK Perhotelan 45 Mataram using Wemos D1 R2 microcontroller, loT-based fingerprint sensor with MQTT protocol to communicate, and web-based interface. The total time used to record attendance for 10 respondents was 11,241 seconds, the average time was 1,1241 seconds. Regarding the implementation of this system, the majority of student respondents gave an average of Very Agree as much as $75.756 \%$, Agree 15,152\%, and Enough as much as 6,7576\%. For homeroom teacher respondents, the average percentage of answers obtained were Strongly Agree $62.5 \%$ and $37.5 \%$ Agree answers related to the implementation of the system based on MOS testing.
\end{abstract}

Keywords: Attendace System, Wemos D1, MQTT, Internet of Things.

*Penulis Korespondensi

\section{Pendahuluan}

Sidik jari merupakan salah satu bagian tubuh manusia yang khas dan unik sehingga menjadi identitas yang membedakan seseorang dengan orang lainnya. Salah satu teknologi untuk mengidentifikasi dan mengenali seseorang melalui sidik jarinya adalah teknologi biometric yang dapat mengenali pola sidik jari melalui modul sensor sidik jari optikal. Dengan sifatnya yang unik, kontur sidk jari dan listrik statis pada tubuh digunakan sebagai identitas yang unik yang dapat menhasilkan keamanan yang tinggi, karena tidak mungkin untuk memalsukan sidik jari atau membuat tiruan sidik jari[1][2].

Penggunaan teknologi biometrik sidik jari untuk presensi siswa dapat menjadi solusi yang meminimalisir kecurangan seperti manipulasi atau pemalsuan data kehadiran maupun kekeliruan pada proses pencatatan kehadiran. Selain itu, pencatatan kehadiran yang terkomputerisasi juga diharapkan dapat memicu siswa hadir tepat waktu serta meningkatkan kinerja di sekolah dengan mempermudah proses pencatatan kehadiran siswa secara terkomputerisasi agar data kehadiran langsung masuk ke komputer untuk selanjutnya mudah untuk direkap dan diolah. Selain itu, teknologi biometrik sidik jari memiliki keuntungan seperti katolisitas, keunikan, stabilitas serta kelayakan yang tinggi dengan biaya yang rendah jika dibandingkan dengan teknologi biometrik lainnya seperti pengenalan wajah[1].

Penerapan pencatatan kehadiran secara terkomputerisasi dapat dilakukan dengan memanfaatkan konsep Internet of Things (IoT) yang beranggapan bahwa perangkat-perangkat elektronik dapat terhubung satu sama lain untuk berkomunikasi maupun bertukar data secara mandiri melalui jaringan internet[3][4]. Perangkat-perangkat elektronik tersebut saling berkomunikasi dengan menggunakan protokol. Protokol MQTT (Message Queue Telemetry Transport) merupakan salah satu protokol yang dapat 
digunakan untuk komunikasi data dalam konsep loT, dengan sifat lightweight message dan didesain untuk perangkat-perangkat dengan sumber daya terbatas[5][6][7].

Sekolah Menengah Kejuruan (SMK) Perhotelan 45 Mataram merupakan sebuah Sekolah Menengah Kejuruan yang berdiri di bawah Yayasan 45 Mataram, terletak di Jalan Imam Bonjol Kecamatan Cakranegara, Mataram. Kegiatan belajar di SMK Perhotelan 45 Mataram setiap hari dimulai pada jam 7.30 WITA, dan selesai pada pukul 15.00 WITA. Lima belas menit Lima belas menit sebelum memulai kegiatan belajar, wali kelas melakukan presensi atau pencatatan kehadiran untuk mendata kehadiran fisik siswa di sekolah, begitu juga sebelum pulang sekolah. Presensi yang dilakukan masih menerapkan sistem konvensional dengan menulis keterangan presensi siswa pada selembar kertas daftar hadir yang berisi nama siswa serta kolom jam datang (JD) dan jam pulang (JP) untuk digunakan selama sebulan. Daftar hadir siswa tersebut dikumpulkan kepada guru Bimbingan dan Konseling (BK) untuk direkap dan ditindaklanjuti.

\section{Tinjauan Pustaka}

Implementasi konsep loT pada sistem absensi siswa di kelas sebelumnya telah banyak dilakukan. Umumnya menggunakan protocol HTTP dan berbasis web. Salah satu penelitian tentang presensi sidik jari diimplementasikan pada sebuah server terdedikasi. Perangkat portable dirancang untuk memungkinkan setiap siswa dapat melakukan presensi selama perkuliahan. Verifikasi kehadiran siswa dilakukan menggunakan modul sidik jari R-305. Data siswa didaftarkan dalam modul sidik jari. Setelah pengenalan pola sidik jari berhasil dilakukan, data kehadiran siswa siap dikirim ke server web. Data ini dikirim melalui antarmuka serial Arduino yang menyediakan urutan data yang merupakan kombinasi dari ID siswa, ID pengajar, dan ID alat misalnya nomor unik dari perangkat keras, sehingga kehadiran tidak akan dapat dipalsukan. Kombinasi ini kemudian dikirim ke server web menggunakan Modul Wi-Fi esp8266-01. Kombinasi ini harus dikirim ke server-web untuk diterjemahkan. Agar nilai ini dapat mencapai server web, esp8266 menyediakan koneksi nirkabel ke access point, yang berada dalam jangkauan, dan kredensial yang tersedia. Esp8266 mendapatkan akses internet dari akses point (AP), yang melayani Set Identifie (SSID) dan password yang sudah dimasukkan dalam dalam modul Esp8266. Setelah kombinasi mencapai server web, skrip PHP melakukan pekerjaan berikutnya, untuk menerjemahkan data, dan basis data MySQL diperbarui. Data dari database diambil dan dikirim ke website untuk tampilan yang mudah dilihat oleh siswa. Seluruh sistem diimplementasikan pada server web khusus. Sebagai hasilnya, perilaku real-time dapat dianalisis, yang membantu kita memahami latensi dan efisiensi[8]

Terdapat pula penelitian lain yang berkaitan dengan presensi sidik jari mengenai rancang bangun sistem informasi absensi sidik jari dengan menggunakan konsep internet of things, dalam pengembangan sistemnya membuat perangkat otentikasi biometrik sidik jari menggunakan modul sensor sidik jari yang terintegrasi dengan perangkat Raspberry Pi 3 untuk memproses fitur transmisi data dan data gambar dari sensor sidik jari ke server. Proses verifikasi dilakukan di server. Sistem informasi absensi sidik jari berbasis web terintegrasi dengan API SIA Universitas Mataram yang dilengkapi dengan sistem otentikasi sidik jari. Absensi sidik jari berbasis web memiliki kemampuan untuk mencatat kehadiran siswa dan rekapitulasi kehadiran siswa. Berdasarkan penelitian yang telah dilakukan, didapatkan hasil berupa : verifikasi penelitian eksperimental masih belum akurat di mana presentase akurasi adalah $24,08 \%$ sehingga dibutuhkan pengembangan terkait metode pencocokan fitur sidik jari pada sistem yang dibangun, dikarenakan proses verifikasi sidik jari masih kurang akurat pada bagian perangkat sensor sidik jari (masih menggunakan metode manhattan distance dan K-Nearest Neighbour)[9].

Penelitian selanjutnya tentang rancang bangun sistem presensi fingerprint yang membangun pengolahan sidik jari terpusat, dimana seluruh sensor sidik jari yang tersebar proses pengolahan dan identifikasinya dilakukan pada satu server terpusat Ketika pengguna melakukan registrasi sidik jari, sensor yang digunakan melakukan ekstraksi fitur gambar sidik jari kemudian mengirimnya ke database, dan meneruskan data sidik jari tersebut ke setiap sensor yang ada. Hasil pengujian menunjukkan bahwa pengginaan Raspberry Pi dan aduino sebagai pengolah data terpusat dapat dilakukan untuk sensor sidik jadri yang tersebar dengan akurasi yang baik[1].

Penelitian serupa rancang bangun sistem absensi dilakukan oleh penulis lain di SMA Negeri 1 Sungai Lilin menggunakan Fingerprpint terintegrasi SMS gateway pada penelitian lainnya menggunakan metode pengembangan prototype dan menggunakan bahasa pemrograman PHP dan database MySQL. Hasil yang didapatkan yaitu dengan sistem absensi yang telah didijitalisasi dan berbasis komputer, pengguna tidak perlu lagi melakukan pencatatan kehadiran 
secara manual atau konvensional. Sistem informasi yang dibangun memiliki fitur untuk melakukan pencarian dan juga memberikan hasil rekap data kehadiran siswa. Wali kelas siswa dapat mengkases Laporan kehadiran, serta melakukan pengelolaan data kehadiran yang valid dan reliabel. Namun, pada sistem informasi yang dibangun belum terdapat fitur untuk membuat laporan berdasarkan kelas [10].

\subsection{Internet of Things}

Internet of Things (IOT) merupakan suatu jaringan yang menghubungkan berbagai objek yang memiliki identitas pengenal serta alamat IP, sehingga dapat saling berkomunkasi dan bertukar informasi mengenai dirinya maupun lingkungan yang diinderanya. Objekobjek dalam loT dapat menggunakan maupun menghasilkan layanan-layanan dan saling bekerjasama untuk mencapai suatu tujuan bersama. Dengan kemampuannya ini, loT telah menggeser definisi internet sebagai komputasi dimana saja kapan saja bagaimana saja, menjadi apa saja siapa saja dan layanan apa saja[11]

\subsection{MQTT (Message Queue Telemetry Transport)}

MQTT adalah salah satu model sistem terdistribusi yang digunakan untuk komunikasi antar perangkat dengan sistem publish/subscribe (PUB/SUB). Message Queue Telemetry Transport (MQTT) adalah sebuah protokol komunikasi data machine to machine (M2M) yang berada pada layer aplikasi, MQTT bersifat lightweight message artinya MQTT berkomunikasi dengan mengirimkan data pesan yang memiliki header berukuran kecil yaitu hanya sebesar 2 bytes untuk setiap jenis data, sehingga dapat bekerja di dalam lingkungan yang terbatas sumber dayanya seperti kecilnya bandwidth dan terbatasnya sumber daya listrik, selain itu protokol ini juga menjamin terkiriminya semua pesan walaupun koneksi terputus sementara, protokol MQTT menggunakan metode publish/subscribe untuk metode komunikasinya[5]

\subsection{Absensi}

Menurut Kamus Besar Bahasa Indonesia, absen adalah tidak masuknya seorang siswa/pegawai pada saat hari masuk/kerja karena sakit, izin, alpa, atau cuti. Sedangkan absensi adalah daftar kehadiran pegawai/siswa, yang berisi jam datang, jam pulang, serta alasan/keterangan kehadiran pegawai. Absensi adalah daftar kehadiran pegawai/siswa/guru yang berisi jam datang dan jam pulang serta alasan atau keterangan kehadirannya. Absensi ini berkaitan dengan penerapan disiplin yang ditentukan oleh masing-masing perusahaan atau institusi[12]

\subsection{Fingerprint}

Kata fingerprint berasal dari bahasa Inggris yang berarti sidik jari. Sidik jari adalah gurat-gurat yang terdapat di kulit ujung jari. Sidik jari berfungsi untuk memberi gaya gesek lebih besar agar jari dapat memegang benda lebih erat[13]. Sidik jari setiap orang memiliki perbedaan baik pada orang kembar sekalipun. Hal ini membeuat sidik jari tepat digunakan dalam teknologi biometric. Keunggulan lainnya dari sidik jari adalah kepraktisannya dan ketahanannya[14].

\section{Metode Peneltian}

\subsection{Rencana Penelitian}

Rencana pelaksanaan penelitian Sistem Presensi Siswa berbasis Internet of Things menggunakan Sensor Sidik Jari pada SMK Perhotelan 45 Mataram, digambarkan dalam flowchart pada Gambar 1:

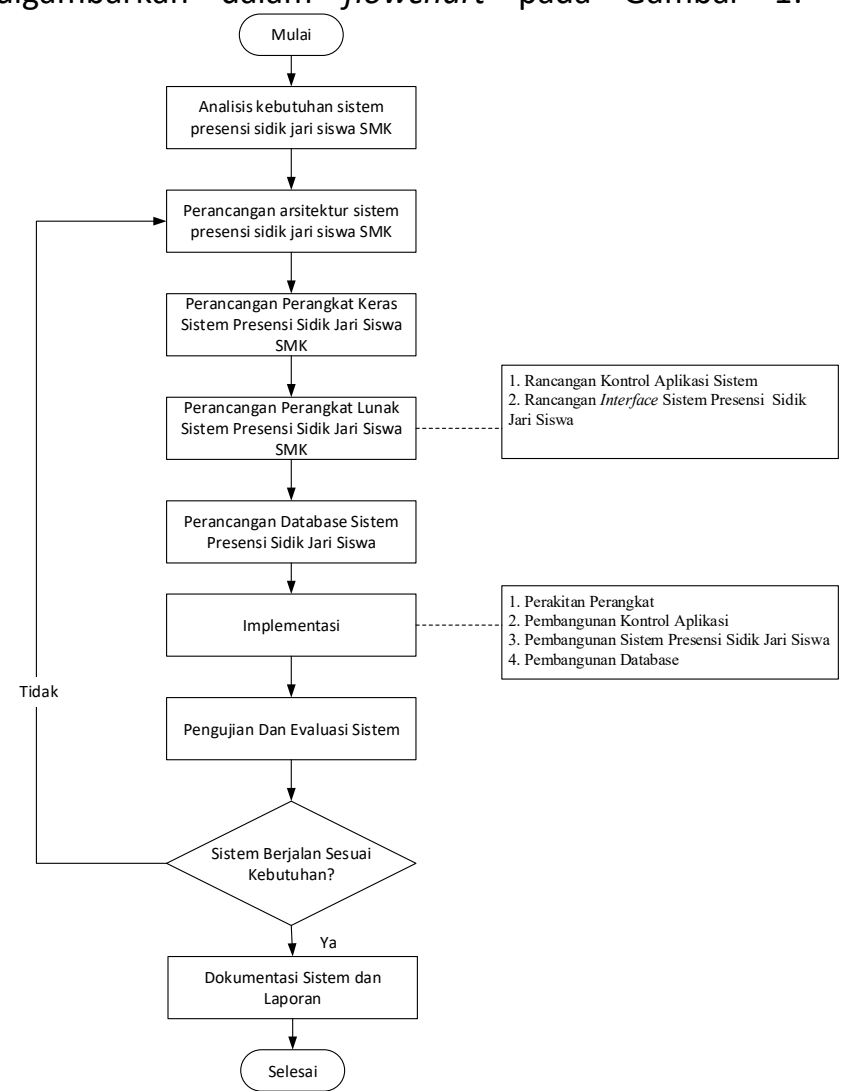

Gambar 1. Diagram Alir Rencana Pelaksanaan Penelitian

\subsection{Perancangan Arsitektur Sistem}

Pada tahap perancangan arsitektur sistem akan dilakukan perancangan terhadap arsitektur dari sistem absensi RFID yang akan dibangun. Adapun 
beberapa penjelasan dari rancangan arsitektur sistem berikut ini :

1) Siswa melakukan enrolment untuk mendaftarkan sidik jarinya dengan meletakkan jarinya pada modul sensor sidik jari.

2) Mikrokontroler Wemos D1 R2 memerintahkan sensor untuk mengambil data sidik jari siswa. Sidik jari siswa akan tersimpan sebagai ID bertipe unsigned integer yang tersimpan di memory sensor sidik jari.

3) Ketika proses absensi, data yang didapat dari sensor sidik jari, dikirim oleh mikrokontroler Wemos ke broker MQTT di (broker.mqttdashboard.com) melalui jaringan internet menggunakan Wi-Fi.

4) Data yang telah di upload ke broker, akan diakses oleh script PHP pada computer/pc sekolah yang terhubung dengan internet. Untuk disimpan pada database local sehingga dapat divisualisasikan melalui aplikasi web presensi siswa yang dikerjakan oleh penulis lain.

5) Data kehadiran siswa di database local diperbaharui. Script PHP tersebut juga akan mengakses database dan mengambil nama siswa pada data presensi terakhir yang masuk untuk dikirim melalui broker ke Wemos.

6) Saat proses absensi siswa berhasil dilakukan, Wemos akan menerima data nama siswa yang diambil dari database oleh script PHP dan dirikirim melalui broker (broker.mqttdashboard.com) sehingga dapat ditampilkan pada OLED display.

7) Visualisasi data absensi siswa dapat diakses oleh wali kelas melaui web prsesensi siswa pada PC sekolah.

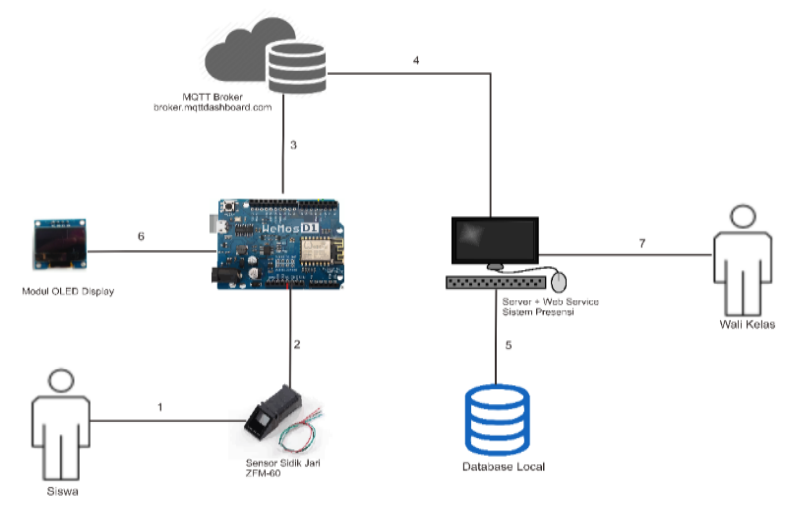

Gambar 2. Rancangan Arsitektur Sistem

\subsection{Rancangan Perangkat Keras}

Untuk membangun sistem absensi sidik jari ini, diperlukan rancangan perangkat keras yang terdiri dari Mikrokontroler Wemos D1 R2 yang berfungsi untuk mengontrol sebuah modul sensor sidik jari dan modul OLED display yang disambungkan menggunakan kabel jumper. Rancangan perangkat keras sistem dapat dilihat pada Gambar 3.

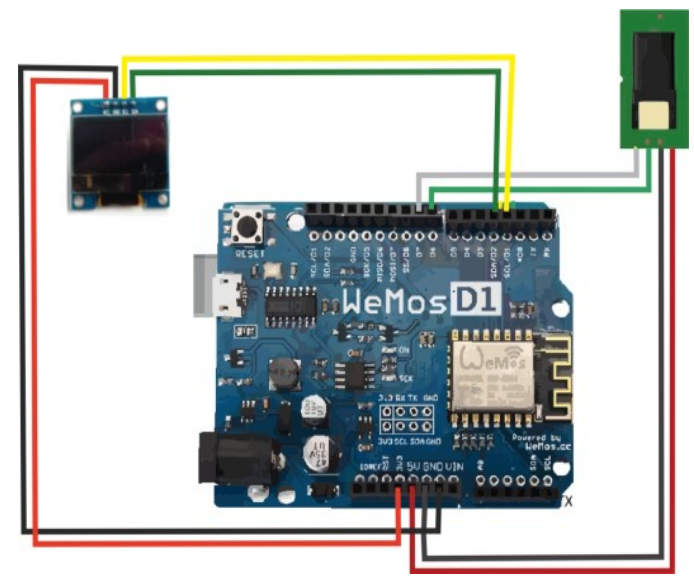

Gambar 3. Rancangan Perangkat Keras

\subsection{Rancangan Database}

Pada perancangan sistem informasi absensi berbasis lot ini memiliki 4 entitas yaitu entitas seperti pada gambar 4. Pada sistem yang diusulkan, terdapat beberapa entitas seperti Kelas, Siswa, dan Sidikjari. Entitas siswa memiliki atribut-atribut seperti nama, NIS, alamat, id_kelas, id_sidik jari. Entitas ini berelasi $\mathrm{N}$ ke 1 dengan entitas Kelas, dimana banyak siswa dapat terdaftar di satu kelas. Siswa juga berelasi 1 ke 1 dengan Sidikjari sebagai sistem presensi yang dapat menangani presensi untuk banyak siswa yang menghasilkan atribut relasi tanggal, jam_datang, jam_pulang dan keterangan. Adapun entitas WaliKelas memiliki atribut nama, JK dan id_walikelas, alamat sebagai primary key nya berelasi 1 ke 1 dengan Kelas. Satu Kelas hanya terdapat 1 WaliKelas. Berikut ini rancangan database dari sistem yang akan dibangun dapat dilihat pada gambar 4 .

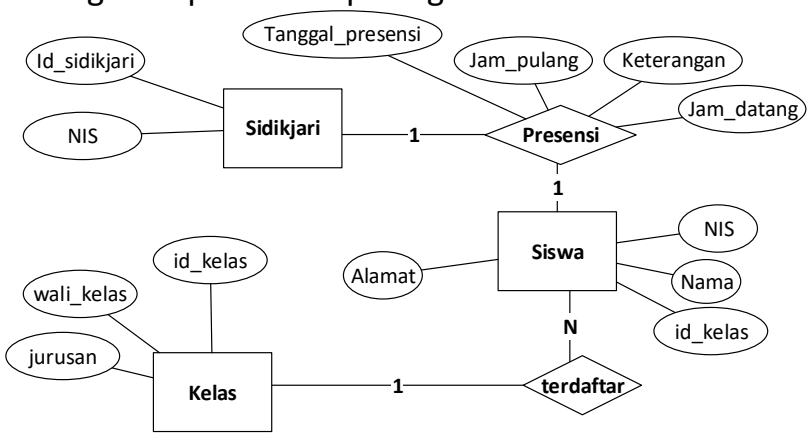

Gambar 4. Rancangan Database

\subsection{Rancangan Perangkat Lunak}

Rancangan perangkat lunak dibuat menggunakan diagram UML. Unified Modelling Language (UML) 
merupakan keluarga notasi grafis yang didukung oleh meta model yang membantu pendeskripsian dan desain sistem perangkat lunak berorientasi objek.

\subsection{Rancangan control application}

Control application adalah aplikasi yang akan dibangun dengan bahasa $\mathrm{C}$ melalui aplikasi Arduino IDE untuk diimplementasikan pada microcontroller Wemos sebagai pengendali modul fingerprint sensor untuk mendapatkan data sidik jari siswa selama proses enrolment sampai proses absensi, menghubungkan perangkat ke internet, serta melakukan pengiriman dan penerimaan data dari dan ke broker MQTT. Selain itu, control application juga dibangun dengan menggunakan bahasa Python untuk menerima data yang dikirim dari Wemos ke broker MQTT dan memasukkannya ke database di server local.

Control application yang dibangun dengan bahasa Python akan menghubungkan server local dengan server MQTT, begitu juga dengan control application pada microcontroller yang akan menghubungkannya dengan server MQTT dengan host broker.mqtt-dashboard.com. Proses identifikasi dilakukan pada modul sensor sidik jari dengan algoritma khusus yang telah terdapat di dalamnya.

Pada proses enrol, siswa akan didaftarkan sidik jarinya pada modul sensor dan diberi ID sebagai pengenal sesuai dengan data siswa tersebut yang telah didaftarkan pada database sistem. Data template sidik jari siswa yang dikenali sebagai ID, tersimpan pada modul sensor. Sehingga pada proses absensi, ketika siswa meletakkan jari yang sudah terdaftar pada proses enrol, jika sidik jari dikenali, maka OLED display akan menampilkan ID sidik jari beserta nama siswa sesuai dengan NIS siswa yang bersangkutan yang menandakan siswa telah berhasil absen dan data kehadiran di database telah diperbaharui. Jika tidak dikenali atau error akan ditampilkan pesan sesuai kondisi pada OLED display. Untuk mencegah kegagalan proses absensi karena kerusakan sidik jari maka ketika dilakukan enrol, tiap mahasiswa mendaftarkan lebih dari 1 jari.

\subsection{Rancangan Sistem Absensi Sidik Jari}

Sistem absensi sidik jari ini dibuat menggunakan pemrogaman berorientasi objek dengan bahasa PHP dengan framework Codelgniter. Pengembangan aplikasi web ini berbasis pada framework Codeigniter dengan rancangan usecase sebagai berikut:

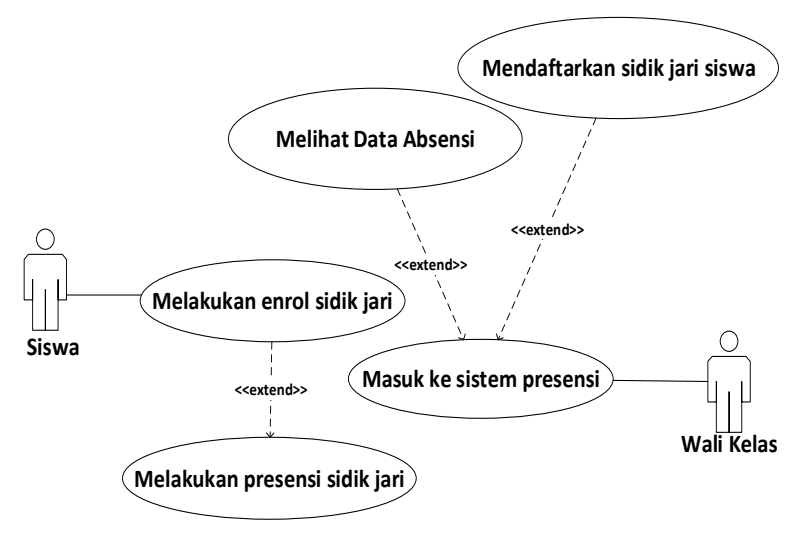

Gambar 5. Use Case Diagram Sistem Absensi Sidik Jari

\subsection{Implementasi Sistem}

Setelah melewati tahap perancangan, kemudian dilakukan proses implementasi sistem. Proses ini terdiri dari :

\subsubsection{Penyusunan Perangkat}

Pada tahap ini, perangkat keras yang dibutuhkan untuk membangun sistem presensi siswa disusun berdasarkan rancangan dan perangkat keras dan alat serta bahan yang telah dibuat sebelumnya.

\subsubsection{Pembangunan Database}

Database yang digunakan pada sistem absensi ini dibangun menggunakan MySQL dengan aplikasi XAMPP ver.3.2 sebagai database local yang akan menyimpan data yang diakses dari broker di cloud.

\subsubsection{Pembangunan Web Service}

Untuk memvisualisasi data digunakan aplikasi web yang dibangun dengan bahasa pemrograman PHP menggunakan framework Codelgniter.

\subsection{Pengujian Sistem}

Tahap pengujian sistem merupakan proses yang bertujuan untuk memastikan sistem yang dibuat dapat berjalan sesuai dengan kebutuhan pengguna. Pada tahap ini, alat absensi sidik jari dan sistem yang dibangun akan diuji menggunakan pengujian Black Box, Mean Opinion Score(MOS) dan pengujian waktu identifikasi sidik jari ketika presensi.

Metode Black-Box testing berfokus pada spesifikasi dan fungsionalitas sistem dengan melakukan pengujian program oleh pengembang dengan memberikan input tertentu dan melihat hasil yang didapatkan dari input tersebut. Pengujian Black Box cenderung untuk menemukan fungsi yang tidak benar atau tidak ada, kesalahan antarmuka, kesalahan 
pada struktur dan akses basis data, kesalahan performaansi, kesalahan inisialisasi dan terminasi.

Pengujian ini melibatkan sampel siswa kelas XII jurusan multi media SMK 45 Mataram sebanyak 9 orang, sampel siswa kelas $\mathrm{X}$ jurusan multimedia SMK Nurul Huda sebanyak 5 orang, dan masyarakat umum untuk mengetahui fungsi dari sistem yang digunakan apakah sudah berjalan sesuai kebutuhan fungsional dan desain yang telah dibuat atau tidak serta mengetahui opini pengguna terhadap performa sistem presensi siswa yang dibuat.

\section{Hasil dan Pembahasan}

\subsection{Realisasi Perangkat}

Realisasi perangkat keras dari sistem berdasarkan perancangan perangkat keras pada Gambar 3 dapat dilihat sebagai berikut :
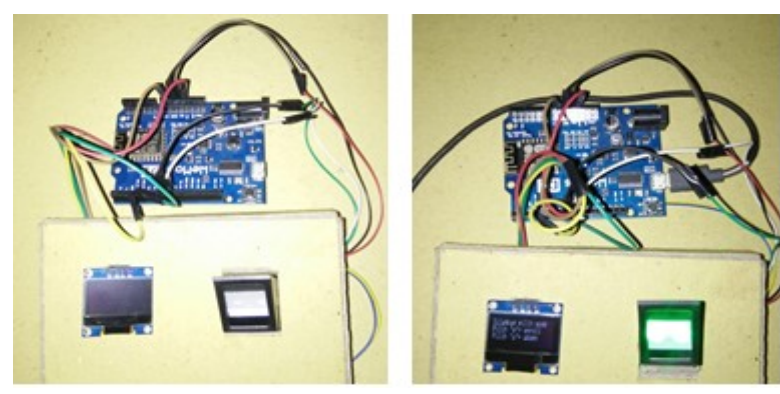

Gambar 6. Realisasi perangkat keras yang digunakan

Pada gambar 6 merupakan perangkat keras yang digunakan, dimana masing-masing modul yang digunakan untuk merealisasikan rancangan sistem telah dipilih sesuai dengan fungsi yang dibutuhkan oleh sistem. Wemos D1 R2 berfungsi sebagai microcontroller berbasis ESP8266 yang dapat terhubung dengan Wi-Fi . OLED display digunakan untuk menampilkan proses yang terjadi ketika sistem digunakan, seperti menampilkan ID dan nama siswa ketika melakukan enrol/presensi. Adapun modul sensor sidik jari berfungsi untuk mengambil fitur/template sidik jari siswa ketika melakukan enrol (pendaftaran sidik jari) maupun presensi.

\subsection{Realisasi Interface Sistem}

Berikut ini merupakan realisasi tampilan interface sistem ketika pertama dibuka. Interface sistem ini berfungsi untuk menampilkan data siswa dan data presensi yang dilakukan melalui sensor sidik jari. Ketika halaman pertama kali dimuat pada browser, sistem akan langsung menyambungkan koneksi ke broker MQTT. Namun apabila ketika halaman dimuat dalam keadaan perangkat computer sedang tidak terkoneksi internet, maka akan ditampilkan pesan alert bertuliskan "Connection Failed" dan sistem tidak akan dapat berkirim pesan ke perangkat sistem presensi sidik jari.

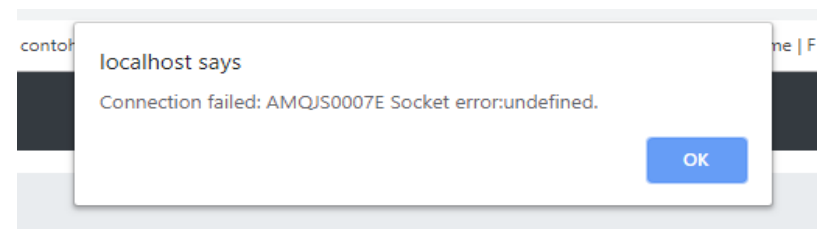

Gambar 7. Tampilan Halaman Interface Ketika Tidak Terkoneksi Internet

Tampilan pertama yang akan dimunculkan sistem ini adalah halaman Data Siswa yang akan menampilkan table data siswa dari database dan tombol Enrol/re-Enrol. Ketika siswa belum mendaftarkan sidik jarinya, maka pada kolom Id Sidik Jari akan berisi keterangan "Belum Melakukan Enrol" dan kolom Opsi akan menampilkan tombol button Enrol. Apabila siswa telah melakukan enrol sidik jari dan memiliki ID sidik jari, maka ID sidik jari tersebut akan ditampilkan pada kolom Id Sidik Jari dan button pada kolom Opsi akan berubah menjadi button reEnrol.

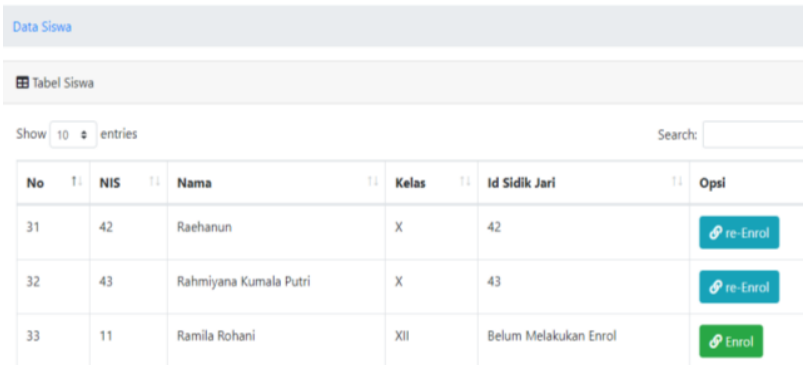

Gambar 8. Realisasi Tampilan Interface Halaman Data Siswa

Berikut ini merupakan tampilan pop-up yang akan muncul ketika pengguna menekan tombol button Enrol. Pop-up tersebut akan berisi nama dari siswa yang belum memiliki ID sidik jari dan hendak didaftarkan sidik jarinya. Data ID sidik jari hanya dapat diisi dengan angka untuk menghindari ketidakseragaman format ID sidik jari. Setelah memasukkan ID dan menekan button Enrol pada pop-up tersebut, maka sistem akan mengirim ID tersebut ke perangkat sensor sidik jari melalui broker MQTT sehingga akan mengaktifkan mode enrol perangkat tersebut.

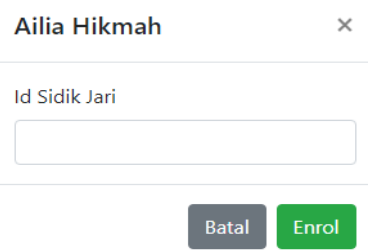

Gambar 9. Form Enrol Sidik Jari

Button re-Enrol tersebut memungkinkan siswa untuk mendaftar ulang sidik jari nya dengan ID yang 
sama dengan yang telah terdaftar. Hal ini untuk mengatasi kondisi ketika siswa ingin mengganti sidik jari yang terdaftar untuk presensi karena alasan tertentu, misalnya: siswa mengalami luka pada jari yang telah didaftarkan sidik jarinya.

Setelah siswa melakukan presensi melalui perangkat sistem presensi sidik jari, data kehadiran tersebut akan ditampilkan pada halaman Data Presensi. Pada halaman ini berisi table yang datanya diambil dari tabel presensi di database sistem dengan field kolom Nama, Tanggal Presensi, dan waktu presensi (Jam Datang dan Jam Pulang) yang akan diurutkan secara menurun. Data presensi terbaru akan ditampilkan di urutan paling atas.

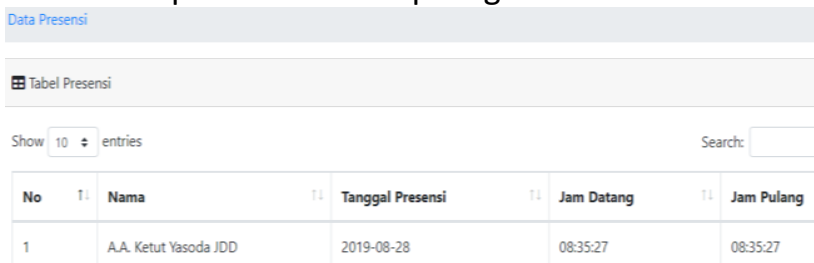

Gambar 10. Realisasi Tampilan Interface Halaman Data Presensi

\subsection{Pengujian Mean Opinion Score (MOS)}

Pengujian ini dilakukan untuk mengetahui kualitas sistem berdasarkan opini/pendapat pengguna yang didapatkan melalui penyebaran kuesioner terhadap pengguna yang mencoba menggunakan sistem. Pengguna sebagai responden akan memberikan pernyataan berupa rentang nilai yang telah ditentukan pada kuesioner. Metode perhitungan pada pengujian kuesioner ini adalah metode kuantitatif, yaitu hasil pengujian didefinisikan dalam suatu nilai angka. Berikut ini adalah rentang nilai yang digunakan pada pengujian MOS untuk sistem ini[9], [15]:

$$
\begin{aligned}
& 1 \text { = Sangat tidak setuju } \\
& 2 \text { = Tidak setuju } \\
& 3=\text { Cukup } \\
& 4=\text { Setuju dan } \\
& 5 \text { = Sangat setuju. }
\end{aligned}
$$

Berdasarkan jawaban tersebut, langkah selanjutnya adalah menghitung persentase dari setiap jawaban yang diberikan oleh pengguna pada masingmasing pernyataan. Persamaan (1) untuk menghitung persentase nilai kuesioner.

Persentase jawaban $=\frac{J}{N} * 100 \%$ dimana:

J : total nilai jawaban yang diberikan pengguna pada setiap nomor.

$N$ : jumlah pengguna.
Lalu, untuk menghitung persentase rata-rata dari setiap poin jawaban, perhitungan yang digunakan adalah menggunakan Persamaan (2)

$$
\text { Rata }- \text { rata }=(\text { Persentase } k e-1+
$$$$
\cdots . .+ \text { Persentase ke }-n) / n
$$

Pengujian ini diterapkan kepada 30 orang pengguna umum(mahasiswa, guru, praktikis IT) yang bertindak sebagai admin/wali kelas untuk mendaftarkan sidik jari siswa. Pengujian yang dilakukan kepada mahasiswa mencakup kinerja sistem perangkat sensor sidik jari. Berikut ini merupakan disiapkan pada kuesioner pengujian Sistem Presensi Sidik Jari Berbasis Internet of Things menggunakan Sensor Sidik Jari pada SMK 45 Mataram:

a. Pertanyaan untuk wali kelas

1. Apakah fungsi Enrol/re-Enrol sudah berjalan dengan baik sesuai dengan fungsinya?

2. Apakah data presensi pada interface sistem presensi sudah sesuai dengan data yang dikirim dari sensor?

3. Apakah sistem presensi sidik jari dapat memenuhi kebutuhan wali kelas dalam proses pencatatan kehadiran?

4. Apakah Interface sistem presensi mudah dipahami dan digunakan (user friendly) ?

b. Pertanyaan untuk siswa

1. Apakah sistem dapat memenuhi kebutuhan siswa dalam proses pencatatan kehadiran?

2. Apakah peralatan presensi (sensor sidik jari) mudah digunakan?

3. Apakah proses pencatatan kehadiran pada peralatan presensi siswa sudah cepat(responsive)?

Pertanyaan tersebut merepresentasikan kebutuhan pengguna pada sistem yang dibangun. Dari pertanyaan tersebut, nilai yang didapatkan dari pengisisan kuesioner masing-masing kelompok responden yng dihitungan menggunakan Persamaan (2), sajikan pada Tabel I.

Tabel I Hasil pengujian MOS untuk Siswa.

\begin{tabular}{|c|c|c|c|c|c|}
\hline \multirow{2}{*}{ Pertanyaan } & \multicolumn{5}{|c|}{ Persentase } \\
\cline { 2 - 6 } & $\begin{array}{c}\text { Sangat } \\
\text { Setuju }\end{array}$ & Setuju & Cukup & $\begin{array}{c}\text { Tidak } \\
\text { Setuju }\end{array}$ & $\begin{array}{c}\text { Sangat } \\
\text { Tidak } \\
\text { Setuju }\end{array}$ \\
\hline 1 & $81,818 \%$ & $9,0909 \%$ & $9,0909 \%$ & $0 \%$ & $0 \%$ \\
\hline 2 & $90,909 \%$ & $9,0909 \%$ & $0 \%$ & $0 \%$ & $0 \%$ \\
\hline 3 & $54,54 \%$ & $27,273 \%$ & $11,182 \%$ & $0 \%$ & $0 \%$ \\
\hline Rata-rata & $75,756 \%$ & $15,152 \%$ & $6,7576 \%$ & $0 \%$ & $0 \%$ \\
\hline
\end{tabular}

Tabel I di atas merupakan hasil perhitungan nilai opini responden dari kelas XII Multi Media SMK Perhotelan 45 Mataram sebanyak 11 orang, dan dapat ditarik kesimpulan mengenai hasil rata-rata persentase jawaban seluruh responden. Mayoritas 
siswa sebanyak $81,818 \%$ memberi nilai Sangat Setuju terhadap pertanyaan pertama, bahwa sistem dapat memenuhi kebutuhan siswa dalam proses pencatatan kehadiran, sisanya menjawab Setuju dan Cukup masing-masing sejumlah 9,0909\%. Untuk pertanyaan mengenai kemudahan menggunakan peralatan, mayoritas jawaban responden sebanyak 90,909\% menyatakan Sangat Setuju dan sisanya 9,0909\% menyatakan Setuju. Pertanyaan mengenai kecepatan proses prsensi (responsibilitas perangkat sensor) memperoleh jawaban Cukup sebanyak 11,182\%, Setuju $27,273 \%$ dan $54,54 \%$ responden menjawab Sangat Setuju. Adapun rata-rata jawaban responden keseluruhan mengarah ke pendapat Sangat Setuju sebesar 75,756\%, Setuju sebesar $15,152 \%$ dan dan 6,7576\% memberi nilai Cukup.

Tabel II Pengujian MOS Untuk Wali Kelas

\begin{tabular}{|c|c|c|c|c|c|}
\hline \multirow{2}{*}{ Pertanyaan } & \multicolumn{5}{|c|}{ Persentase } \\
\cline { 2 - 6 } & $\begin{array}{c}\text { Sangat } \\
\text { Setuju }\end{array}$ & Setuju & Cukup & $\begin{array}{c}\text { Tidak } \\
\text { Setuju }\end{array}$ & $\begin{array}{c}\text { Sangat } \\
\text { Tidak } \\
\text { Setuju }\end{array}$ \\
\hline 1 & $75 \%$ & $25 \%$ & $0 \%$ & $0 \%$ & $0 \%$ \\
\hline 2 & $50 \%$ & $50 \%$ & $0 \%$ & $0 \%$ & $0 \%$ \\
\hline 3 & $100 \%$ & $0 \%$ & $0 \%$ & $0 \%$ & $0 \%$ \\
\hline 4 & $25 \%$ & $75 \%$ & $0 \%$ & $0 \%$ & $0 \%$ \\
\hline Rata-rata & $62,5 \%$ & $37,5 \%$ & $0 \%$ & $0 \%$ & $0 \%$ \\
\hline
\end{tabular}

Dari Tabel II di atas dapat ditarik kesimpulan mengenai hasil rata-rata persentase jawaban seluruh responden Wali Kelas terhadap sistem presensi terutama pada bagian Interface. Untuk pertanyaan mengenai kepuasan terhadap fungsi enroll/re-enrol jawaban responden cenderung mengarah ke Sangat Setuju sebanyak $75 \%$. Untuk pertanyaan mengenai kesesuaian data yang dikirim dari perangkat sensor dengan yang ditampilkan pada sistem, sebesar $50 \%$ responden menjawab Setuju dan $50 \%$ sisanya menjawab Sangat Setuju. Pertanyaan mengenai terpenuhinya kebutuhan Wali Kelas untuk proses pencatatan kehadiran siswa, $100 \%$ responden memberi jawaban Sangat Setuju. Penilaian terhadap mudahnya pemahaman terhadap sistem presensi( user friendly) menghasilkan jawaban Setuju sebesar 75\% dan Sangat Setuju sebesar 25\%. Adapun ratarata jawaban responden keseluruhan mengarah ke pendapat Sangat Setuju sebesar $62,5 \%$ dan jawaban Setuju sebesar $37,5 \%$.

\section{Kesimpulan dan SARAN}

\subsection{Kesimpulan}

1. Sistem presensi sidik jari dapat digunakan untuk melakukan proses pencatatan kehadiran secara otomatis dan terkomputerisasi pada SMK 45
Mataram sehingga memudahkan sekolah untuk memonitor kehadiran siswa melalui sistem.

2. Sistem presensi sidik jari yang dibuat dapat digunakan untuk melakukan proses pendaftaran sidik jari dan proses pencatatan kehadiran melalui protocol MQTT, sehingga sangat bergantung pada koneksi internet untuk melakukan pengiriman data presensi.

3. Berdasarkan percobaan yang telah dilakukan, sistem tidak dapat digunakan untuk melakukan proses enrol maupun presensi pada jari dengan sidik jari yang kurang baik atau rusak (sidik jari tidak dapat terbaca), sehingga apabila memungkinkan siswa dapat memilih untuk menggunakan jari tangan yang masih dapat terbaca sidik jarinya.

4. Waktu total yang digunakan untuk melakukan proses pencatatan kehadiran (presensi) untuk 10 orang responden yaitu 11,241 detik dengan nilai waktu tersingkat 1,036 detik dan waktu terlama 1,408 detik. Waktu rata-rata yang didapatkan sebesar 1,1241 detik.

5. Berdasarkan pengujian MOS (Mean Opinion Score), persentase opini responden siswa terhadap penerapan sistem ini rata-rata Sangat Setuju sebanyak 75,756\%, Setuju 15,152\%, dan Cukup sebanyak 6,7576\%. Sedangkan untuk responden wali kelas menghasilkan persentase jawaban ratarata $62,5 \%$ jawaban Sangat Setuju dan 37,5\% jawaban Setuju.

\subsection{Saran}

Berdasarkan kesimpulan yang didapatkan dari hasil pengujian dan evaluasi sistem, untuk memperbaiki kekurangan dan pengembangan sistem diberikan saran sebagai berikut:

1. Sistem yang dibuat tidak dilengkapi dengan fitur pengolahan data presensi, sehingga tidak dapat menangani presensi untuk siswa yang tidak hadir maupun yang memiliki kondisi khusus sehingga sehingga sidik jari tidak terbaca dan tidak dapat menggunakan sidik jarinya untuk pencatatan kehadiran. Untuk itu, di masa mendatang diharapkan penambahan fitur untuk mengolah data siswa yang tidak hadir.

2. Sistem yang dibangun saat ini menggunakan metode pengenalan (identifikasi) sidik jari dan penyimpanan sidik jari pada memori internal sensor dengan kapasitas maksimal 162 sidik jari, sehingga diharapkan penelitian selanjutnya dapat menerapkan metode identifikasi pada server untuk mengatasi keterbatasan kapasitas memori internal sensor. 


\section{DAFTAR PUSTAKA}

[1] H. Siti, "Identifikasi Sidik Jari Sistem Absensi Menggunakan Arduino dan Raspberry Pi," Medan, 2017.

[2] A. S. Rintjap, R. U. A. Sherwin, Sompie, and O. Lantang, "Aplikasi Absensi Siswa Menggunakan Sidik Jari di Sekolah Menengah Atas Negeri 9 Manado," E-Journal Tek. Elektro dan Komput., pp. 1-5, 2014.

[3] Q. Shafi, J. Khan, N. Munir, and N. K. Baloch, "Fingerprint verification over the network and its application in attendance management," ICEIE 2010 - 2010 Int. Conf. Electron. Inf. Eng. Proc., vol. 2, no. Iceie, pp. 555-559, 2010.

[4] K. Saraswathi, B. Jayaram, and R. Balasubramanian, "Retinal Biometrics based Authentication and Key Exchange System.," Int. J. Comput. ..., vol. 19, no. 1, pp. 1-7, 2011.

[5] H. A. Rochman, R. Primananda, and H. Nurwasito, "Sistem Kendali Berbasis Mikrokontroler Menggunakan Protokol MQTT pada Smarthome," J. Pengemb. Teknol. Inf. dan Ilmu Komput., vol. 1, no. 6, pp. 445-455, 2017.

[6] Z. Mindriawan, "Implementasi Internet of Things Pada Sistem Monitoring Suhu dan Kontrol Air Pada Kandang Burung Puyuh Petelur dengan Menggunakan Protokol MQTT," 2018.

[7] H. S. Chandulal and A. D. Patange, "Biometric Door Lock System Using MQTT Protocol,” pp. 9121-9126, 2018.

[8] N. Prince, A. Sengupta, and M. K. Unni,
"Implementation of IOT Based Attendance System on a Dedicated Web-Server," vol. 7, no. 6, pp. 351355, 2016.

[9] L. M. S. Ramadhan, "Rancang Bangun Sistem Informasi Absensi Sidik Jari Terintegrasi SIA UNRAM Menggunakan Konsep Internet of Things," J-Cosine, 2018.

[10] A. A. N. Wahyudi, "Rancang Bangun Sistem Absensi SMA Negeri 1 Sungai Lilin Menggunakan Fingerprint Terintegrasi SMS Gateway," Palembang, 2018.

[11] E. D. Meutia, "Internet of Things - Keamanan dan Privasi," Semin. Nas. dan Expo Tek. Elektro 2015, pp. 85-89, 2015.

[12] Maisaroh, "Implementasi Kebijakan Absen Elektronik Sidik Jari (Finger Print) Terhadap Disiplin dan Kinerja Pegawai Negeri Sipil (PNS) di MIN 1 Teladan Palembang," 2017.

[13] M. P. T. Sulistyanto, D. A. Nugraha, N. Sari, N. Karima, and W. Asrori, "Implementasi IoT (Internet of Things) dalam pembelajaran di Universitas Kanjuruhan Malang," SMARTICS J., vol. 1, no. 1, pp. 20-23, 2015.

[14] B. Gunawan, A.A., Gazali, W., \& Sanjaya, "Analisis Sistem Identifikasi Sidik Jari Berbasis Minuatiae dan Non-Minuatiae," pp. 5-9, 2012.

[15] S. Syaifullah, I. G. P. S. Wijaya, and A. Y. Husodo, "Sistem Informasi Kepuasan Layanan Administrasi Akademik Berbasis IPA (Importance Performance Analysis) Studi Kasus Fakultas Teknik Universitas Mataram," J. Comput. Sci. Informatics Eng., vol. 2, no. 1, 2018. 